\title{
Is it acalculous cholecystitis or reactive/viral pericholecystits in acute hepatitis?
}

\section{TO THE EDITOR}

Dear Editor, we read with great interest the case report written by Dr Souza LJ et al. ${ }^{1}$ titled "Acute acalculous cholecystitis in a teenager with hepatitis A virus infection: a case report" published in the February 2009 issue of the Brazilian Journal of Infectious Diseases. The authors describe a case of acalculous cholecystitis (AC) in a 16-year-old male during an episode of hepatitis A virus infection. Diagnosis of AC had been made on the basis of clinical symptoms and signs supported with sonographic scan evidence. The authors have presented four ultrasonography (USG) scan images (Figures 1-4) supporting a diagnosis of AC. It has been mentioned that the gall bladder wall was thickened and surrounded by echogenic content. After analyzing the USG images carefully, we strongly feel that the given images may not support a diagnosis of AC. The size of the gall bladder (GB) as shown in Figure 1 appears rather small. Besides, there has been no mention about any abnormality of the GB contents. Mere presence of gall bladder wall thickening and pericholecystic fluid is not enough for a diagnosis of $\mathrm{AC}$ as such findings are not uncommon in acute hepatitis without AC. ${ }^{2}$

Figure 1: Ultrasonography - thickness of the gall bladder wall $(7.0 \mathrm{~mm})$.

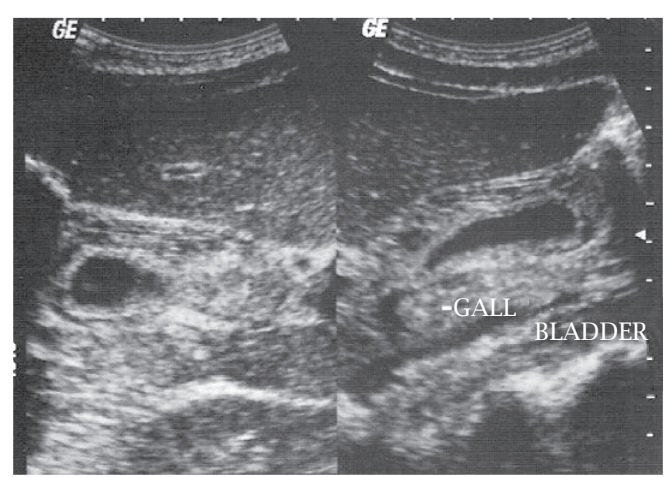

Figure 2: Ultrasonography - hepatomegaly.

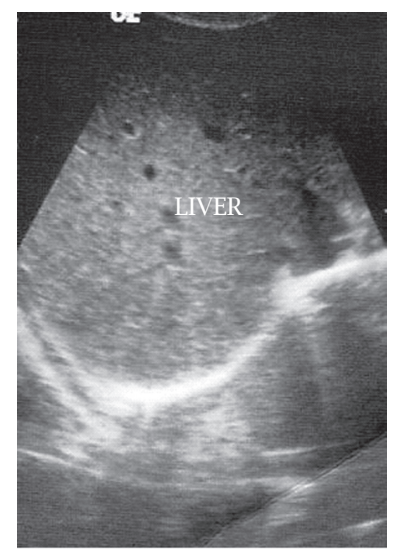

Figure 3: Ultrasonography - thickness of the gall bladder wall.

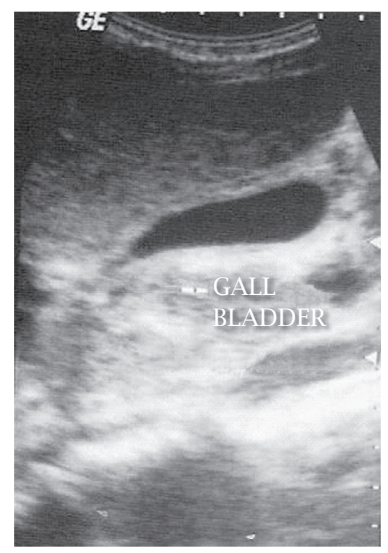

Figure 4: Ultrasonography - small quantity of fluid at the anterior wall of the liver.

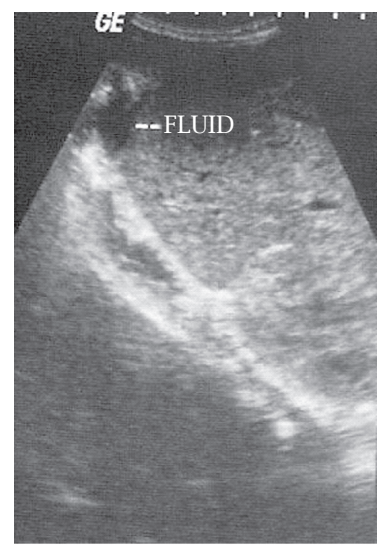

Authors

Jyotindu Debnath

Ankit Mathur

${ }^{1} \mathrm{MD}$, Senior Adviser, Radiology 167 Military Hospital Punjab, India.

${ }^{2} \mathrm{MD}$, Classified Specialist, Radiology

167 Military Hospital Punjab, India.
Submitted on: 3/2/2010 Approved on: 3/25/2010

Correspondence to: Dr Jyotindu Debnath Senior Adviser, Radiology Department of Radiodiagnosis \& Imaging 167 Military Hospital Pathankot - India PIN: 91-14001 Phone: 91-9216915034 Email: jyotindu debnath@rediffmail.com

We declare no conflict of interest. 
AC usually occurs in critically ill patients, e.g., post-operative/trauma patients in ICU settings. Sonographic features of AC include abnormally distended GB, wall thickening, pericholecystic fluid (without ascites) and sludge (in the absence of cholelithiasis). ${ }^{3}$ A variety of GB changes can occur in acute hepatitis regardless of the etiology and include variable degree of GB wall thickening, subnormal GB volume and echogenic bile/ sludge. ${ }^{3}$ Such GB changes are transient, persist for a few days and revert back to normal along with clinical recovery. GB changes in acute hepatitis are mostly thought to be a reactive phenomenon secondary to hepatic inflammation. A second school of thought terms this phenomenon as viral pericholecystitis ${ }^{2}$ and differentiates this entity from more serious AC where the GB is abnormally distended. It is important to differentiate these two entities as the former is a benign transient phenomenon in acute hepatitis and the latter is a potentially serious condition in critically ill patients with poor prognosis.

At our institution, every year, more than 100 patients of acute hepatitis undergo USG evaluation during active disease as well as during the recovery phase as a routine proto- col. Variable degree of GB wall thickening with subnormal GB volume in fasting state is quite common ( $~ 80 \%$, unpublished data) in patients with acute hepatitis. At times there is extreme degree of wall thickening with no visible GB lumen noted despite adequate fasting. Such a patient when examined after a meal shows paradoxical filling of the GB lumen implying that the cystic duct is patent (work in progress).

[Braz J Infect Dis 2010;14(6):647-648] @Elsevier Editora Ltda.

\section{REFERENCES}

1. Souza LJ, Braga LC, Rocha Nde S, Tavares RR. Acute acalculous cholecystitis in a teenager with hepatitis a virus infection: a case report. Braz J Infect Dis. 2009;13:74-6.

2. Rosenthal SJ, Cox GG, Wetzel LH, Batnitzky S. Pitfalls and differential diagnosis in biliary sonography. Radiographics. 1990;10:285-311.

3. Smith EA, Dillman JR, Elsayes KM, Menias CO, Bude RO. Cross-sectional imaging of acute and chronic gallbladder inflammatory disease. Am J Roentgenol. 2009; 192:188-96. 